\title{
Influence of Processing Variables on the Mechanical Behavior of HDPE/clay Nanocomposites
}

\author{
Renata Barbosa ${ }^{\mathrm{a} *}$, Dayanne Diniz Souza Morais ${ }^{\mathrm{b}}$, Karine Castro Nóbrega ${ }^{\mathrm{b}}$, \\ Edcleide Maria Araújo ${ }^{\mathrm{b}}$,Tomás Jeférson Alves Mélo ${ }^{\mathrm{b}}$ \\ ${ }^{a}$ Department of Mechanical Engineering, Federal University of Piauí - UFPI, \\ Campus Minister Petronio Portella, CEP 64049-550, Teresina, PI, Brazil \\ ${ }^{\mathrm{b}}$ Department of Materials Engineering, Federal University of Campina Grande - UFCG, \\ CEP 58429-900, Campina Grande, PB, Brazil
}

Received: March 16, 2011; Revised: May 10, 2012

\begin{abstract}
Nanocomposites were processed using the technique of melt intercalation, starting from a concentrated polar compatibilizer/organoclay (PE-g-MA/organoclay) prepared in an internal mixer. The concentrate was incorporated into the matrix of HDPE by two methods: I) counter-rotating twin-screw extruder and II) co-rotating twin-screw extruder, using two screw profiles (ROS and 2KB90). After extrusion, the specimens of the extruded composites were injection molded. The X-ray diffraction (XRD) technique was used to analyze the degree of expansion of the prepared clays. To analyze the degree of exfoliation of obtained nanocomposites, XRD and TEM (transmission electron microscopy) were used. The influence of processing variables on mechanical properties was studied through the behavior of the modulus and tensile strength of nanocomposite systems. By XRD and TEM, it was seen that the clay was well dispersed in the matrix and the presence of intercalated and partially exfoliated hybrid structure for nanocomposites was observed when the systems were prepared in counter-rotating twin-screw extruder. A similar behavior was observed in the use of screws (2KB90 or ROS) of the nanocomposites, with a reduction in modulus and tensile strength. Although the mixing process by extruding be the most common industrial practice, and also it is the preferred strategy for the preparation of polymer nanocomposites, much of the literature was directed to the study of chemical modification of clay, type and level of compatibilizer, in order to maximize the compatibility between clay and the polymeric matrix. On the other hand, studies about the role of the processing and configurations of screws are relatively scarce. The main motivation of this work was to expand and to contribute to spread a better understanding of the effects of processing to obtain polymer nanocomposites.
\end{abstract}

Keywords: nanocomposites, organoclay, mechanical behavior

\section{Introduction}

In recent years, great attention has been devoted by the polymer materials research community to the study of characteristics of the nanocomposites, especially for what concerns the understanding of the factors which leads to the desired dispersion (nanodispersion) influencing the final material properties ${ }^{1}$.

In particular, researchers have focused their attention on layered silicates (nanoclays) addressing all the possible issues related to the preparation of nanocomposites. It was proven that the addition of nanoclays to a polymer matrix brings unambiguous advantages in terms of improved mechanical properties, thermal stability, fire resistance, gas barrier, etc. ${ }^{2}$.

The smectite clays are commonly used as the dispersed phase to obtain nanocomposites, in particular, bentonite clays, for these present attractive characteristics: naturally small particles with dimensions of average size, less than $2 \mathrm{~mm}$, low cost and their individual layers are reactive. Furthermore, it is possible to exchange the metal ions

*e-mail: rrenatabarbosa@yahoo.com by organic cations from a specific surfactant, usually a quaternary ammonium salt, turning the clay into organoclay $^{3-5}$.

Polymer/clay nanocomposites are normally obtained through the dispersion of chemically modified clays (organoclays) within a polymer matrix or by in situ polymerization, merger, or solution intercalation ${ }^{6-8}$. The melt intercalation is the most promising method for large scale production.

This method consists in mixing the clay in the polymer by conventional techniques of polymer processing, in which the clay is mixed with the polymer above its softening point (for amorphous thermoplastic) or melt (for semi-crystalline thermoplastics), so this penetrates the galleries of the clay (if there is some degree of affinity between the polymer and surfactant presents in the clay) intercalating the lamella and eventually exfoliating them8.

The high density polyethylene (HDPE) is a thermoplastic resin, whose chains have few branches, so it is considered a linear polymer chain, and also for this reason, it has a high 
density compared to low density polyethylene (LDPE). It has one of the simplest structures of polymers on the market, which provides it great versatility for the variety of processes and implementation, resulting in characteristics of density, molecular weight and molecular weight distribution ${ }^{9,10}$.

Several factors affect the state of dispersion of nanocomposites: the type of organic modifier for the clay $^{11,12}$, the properties of polymer matrix ${ }^{13}$ and the type and concentration of compatibilizer in the system ${ }^{14,15}$. All these factors determine whether the polymer can intercalate and/or exfoliate between the layers of organoclay. But the state of exfoliation also seems to be strongly affected by processing and mixing conditions ${ }^{15,16}$. The incorporation of organoclay in the matrix is usually made in twin-screw extruders.

In this study, bentonite clay was modified by cation exchange capacity (CEC) reaction with a quaternary ammonium salt at $100 \%$ of CEC of the clay. The organoclay was mixed with compatibilizer, and the concentrate was incorporated into the HDPE matrix by two methods: I) counter-rotating twin- screw extruder and II) co-rotating twin-screw extruder, using two screw profiles (ROS and 2 KB90) and injection molding. The techniques of X-ray diffraction and transmission electron microscopy were used to analyze the degree of expansion and exfoliation of developed nanocomposites. The interference of processing variables on mechanical properties was studied through the behavior of the elastic modulus and tensile strength of nanocomposite systems.

\section{Materials and Methods}

\subsection{Materials}

The materials used were: bentonite clay (1346), supplied by Bentonit União Nordeste (BUN) industry, located in the city of Campina Grande - PB. The cation exchange capacity (CEC) is approximately $90 \mathrm{mEq} .100 \mathrm{~g}^{-1}$; Praepagen $\mathrm{WB}^{\circledR}$ (PRA - stearyl dimethyl ammonium chloride) quaternary ammonium salt supplied in the gel state, manufactured by Clariant-PE; The used polymer matrix was high density polyethylene HDPE (JV-060U), provided by the Braskem (Camaçari/BA);

To improve the affinity between HDPE matrix and the organoclay was used polar compatibilizer Polybond 3009 (PE-g-MA), MFI = $5 \mathrm{~g} / 10 \mathrm{~min}$, with percentage of functionality of $1 \%$, supplied by Crompton - Additives and olefinic Styrene - São Paulo/SP.

\subsection{Preparation of organoclay and nanocomposites}

The organophilization of clay was accomplished through the exchange of sodium ions present in the lamellar of the clay by ammonium ions to produce the organoclay at $100 \%$ cation exchange capacity (CEC) of the clay, according to studies by Araújo et al. ${ }^{17,18}$

The preparation of systems of HDPE/organoclay/ compatibilizer polar was initially performed with a master of compatibilizer/organoclay (PE-g-MA/Clay) in an internal mixer coupled with to torque rheometer of Haake Bluchler. The master was grounded, and then, it was incorporated into high density polyethylene by two methods: I) counterrotating twin-screw extruder coupled with to torque rheometer of Haake Blüchler, II) co-rotating twin- screw extruder, with the use of two screw profiles ROS and $2 \mathrm{~KB} 90$, (Figure 1).

The 2KB90 screw profile has been used for Polymer Processing Group at the Federal University of São CarlosUFSCar $^{19}$. It is composed of a molten barrier region at the beginning, to ensure that, from that point on, all the material is melted and is composed also by kneading blocks KB45 followed by a reverse step element. The other set of kneading blocks is composed of KB90 two elements. The profile of ROS screw has been studied for more time for obtaining nanocomposites ${ }^{20}$. The profile is composed of a molten barrier near the beginning in the screw and two sets of kneading blocks. The first is composed of elements

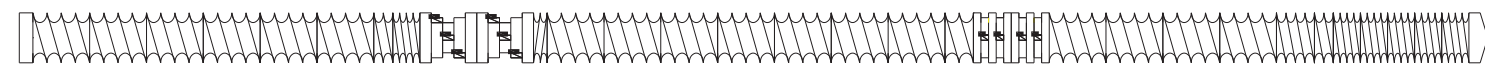

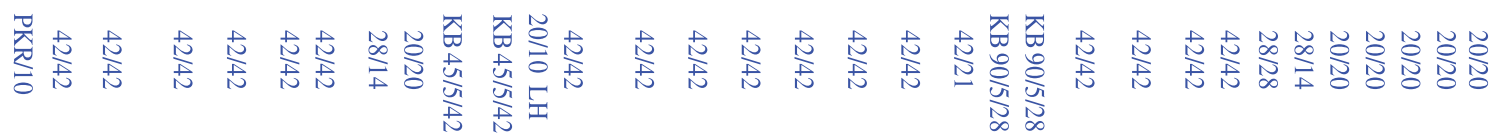

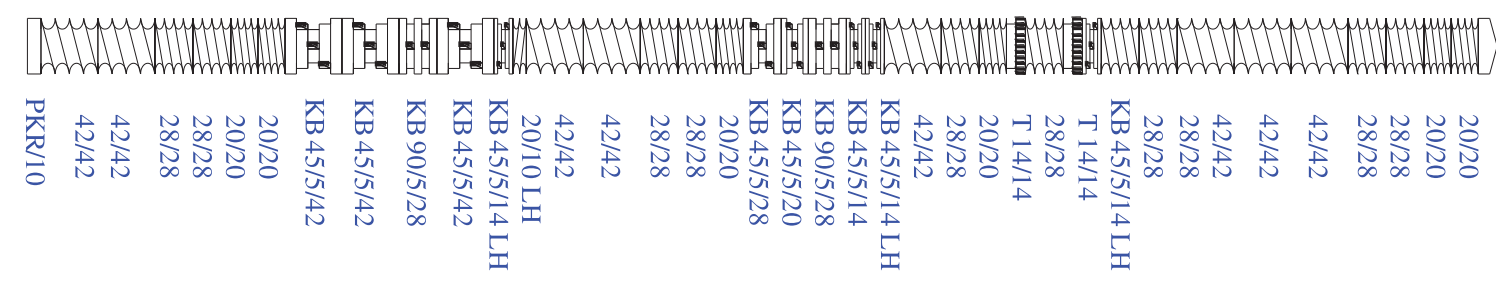

(b)

Figure 1. Screw profiles a) 2KB90 e b) ROS. 
of forward and reverse pitch mixing and the second is composed of elements of the turbine to improve dispersion of the second phase and an element of reverse pitch mixture. After extrusion, the specimens of nanocomposites were molded by injection. For tensile testing, specimens were injection molded in Fluidmec model at a temperature of $200{ }^{\circ} \mathrm{C}$ at all zones, with cooling time of 25 seconds and mold temperature at $40{ }^{\circ} \mathrm{C}$. The used concentration was at a ratio of 91:6:3 (PE: PE-g-MA: Clay).

The characterizations of the systems were made by analysis of X-ray diffraction (XRD) at room temperature by XRD-6000 Shimadzu diffractometer $(40 \mathrm{kV}, 30 \mathrm{~mA}$ ) using $\mathrm{CuK} \alpha$ radiation $(\lambda=0.154 \mathrm{~nm})$ at the rate of $2 \% \mathrm{~min}$ in the range of $1.5-30^{\circ}$.

The structures were observed directly by transmission electron microscopy (TEM). TEM was carried out on a Philips CM120 with an acceleration voltage of $120 \mathrm{kV}$. Samples were cryogenically microtomed into ultrathin sections (25-50 nm thick) from Izod impact bars with a diamond knife using a RMC MT-7000 under cryogenic conditions $\left(-80{ }^{\circ} \mathrm{C}\right)$ inside the microtoming chamber. A cutting speed of $0.1 \mathrm{~mm} / \mathrm{s}$ was maintained throughout the microtoming operation. The ultrathin sections were collected on copper grids.

Tem mechanical characterization was used to observe the influence of modified clay and processing conditions in the properties such as, rigidity and tensile strength. Tensile tests were conducted using a LLoyd LR/10KN Universal Machine at room temperature and crosshead speed of $50 \mathrm{~mm} / \mathrm{min}$ according to the standard ASTM D638 ${ }^{21}$.

\section{Results and Discussion}

\subsection{Diffractograms of clay and nanocomposites by XRD}

Figure 2 shows the organoclay XRD curves (1346-100) and systems processed by the method I (PE 3009 100) and the curve for the same composition by the method II using the two profiles screws, called 2KB90 and ROS (PE 2 KB90 ORG and PE ROS ORG).

It was found that the nanocomposite system PE 3009 100 (method I) showed increased basal interplanar distance $\left(d_{001}\right)$ as compared to organoclay 1346-100, indicating the formation of polyethylene intercalated molecules structures between the layers of organoclay and the presence of two shoulders, probably to $\mathrm{d}_{002}$ and $\mathrm{d}_{003}$ baseline distance respectively, which may indicate that a small portion of the layers of clay was intercalated by polymer molecules ${ }^{22}$.

The co-rotating modular extruder (method II) was used to promote a better dispersion and consequently to obtain exfoliated structures. However, it is observed that these systems presented basal spacing $d_{001}$ smaller than the organoclay and the system processed in the counterrotating twin- screw extruder (method I), indicating that their formation was a microcomposite.

The most likely hypothesis for the basal spacing distance decrease of nanocomposites systems may have been the escape of organic cation of the clay layers during processing or break connections between the surface of the clay silicates and quaternary ammonium salt. This happened due to the effect thermal degradation during processing in the modular extruder, decreasing the basal planar distance between the clay layers ${ }^{23}$.

\subsection{Transmission electron microscopy (TEM).}

The processed systems by method I and observed by TEM demonstrate that the presence of intercalated and partially exfoliated hybrid structure can contribute to the general properties of obtained nanocomposites (Figure 3 ). The TEM photomicrographs of the systems processed by method II present conventional composite structures showing basically aggregates of clay. It was noticed that only the processing is not sufficient for shearing and distributing satisfactorily the load on polymer matrix even with the presence of organoclay and compatibilizers. These data corroborate with XRD results, noting that there was no affinity among the polymer matrix, clay, polar compatibilizers and processing conditions, which may be evidenced by the formation of agglomerates. The clay particles are not well dispersed in polymer matrix, probably due to poor interfacial adhesion, indicated by arrows in photomicrography. Because these screws provide the biggest effects of shearing and increased residence time during processing, it is possible that the quaternary ammonium salt, under these conditions, has migrated from the inside of the layers of clay and/or it has degraded, causing consequently the reduction of basal planar distance, and for that reason aggregates were produced.

\subsection{Mechanical properties of nanocomposites}

Table 1 shows the values of elasticity modulus and tensile strength of high density polyethylene matrix (HDPE 2KB90 and HDPE ROS), the polyethylene/organoclay/PE-g-MA system processed by method II when 2KB90 (PE 2KB90 ORG) and ROS (PE ROS ORG) screws were used. The value of the PE 3009100 refers to the polyethylene/organoclay/ PE-g-MA system and polyethylene matrix (HDPE) obtained by method I. Figure 4 shows the stress $\times$ strain curves of the systems described above.

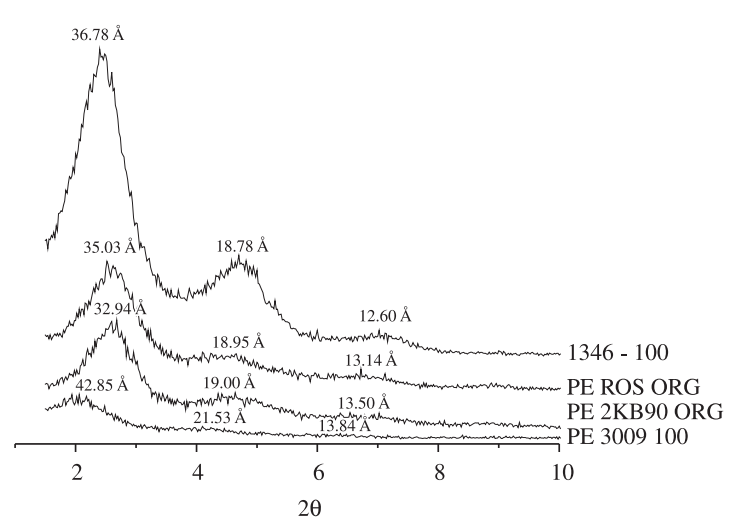

Figure 2. XRD patterns of 1346-100 clay and PE/clay/PE-g-MA systems processed in two extruders: modular co-rotating (2KB90 and ROS) and counter-rotating (PE 3009 100). 

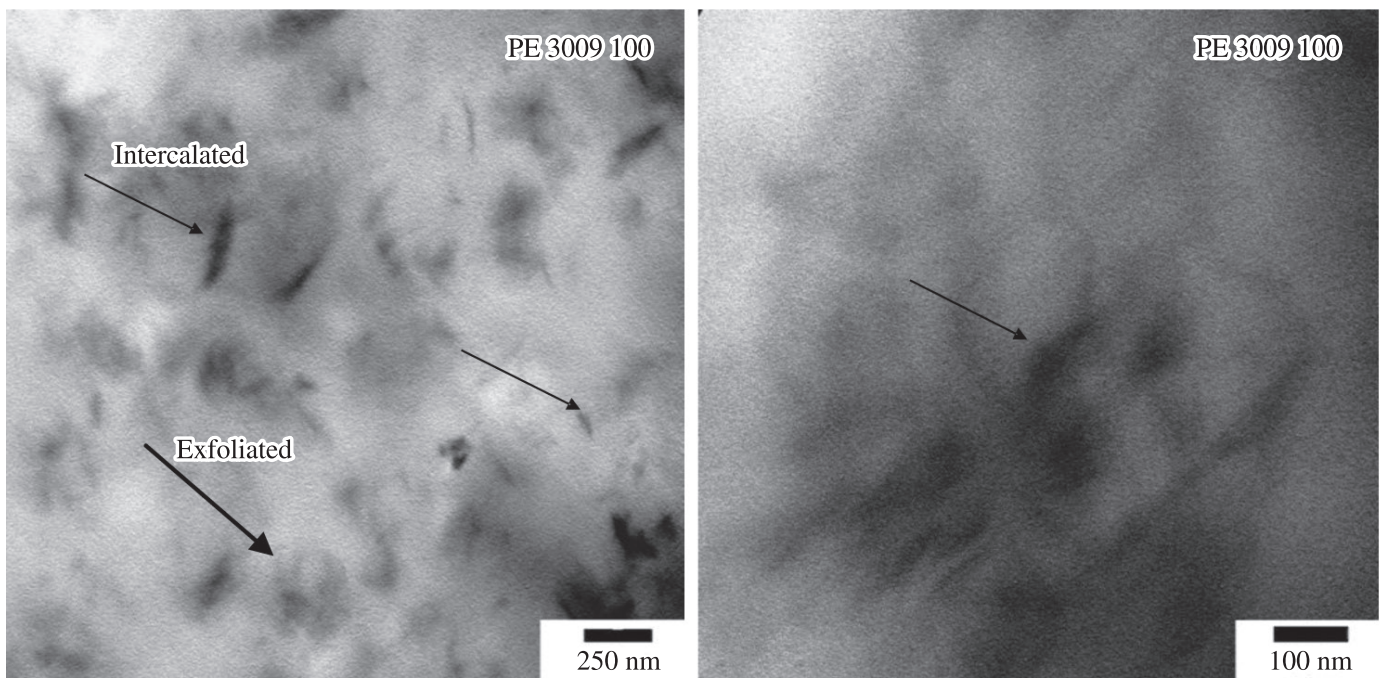

(a)
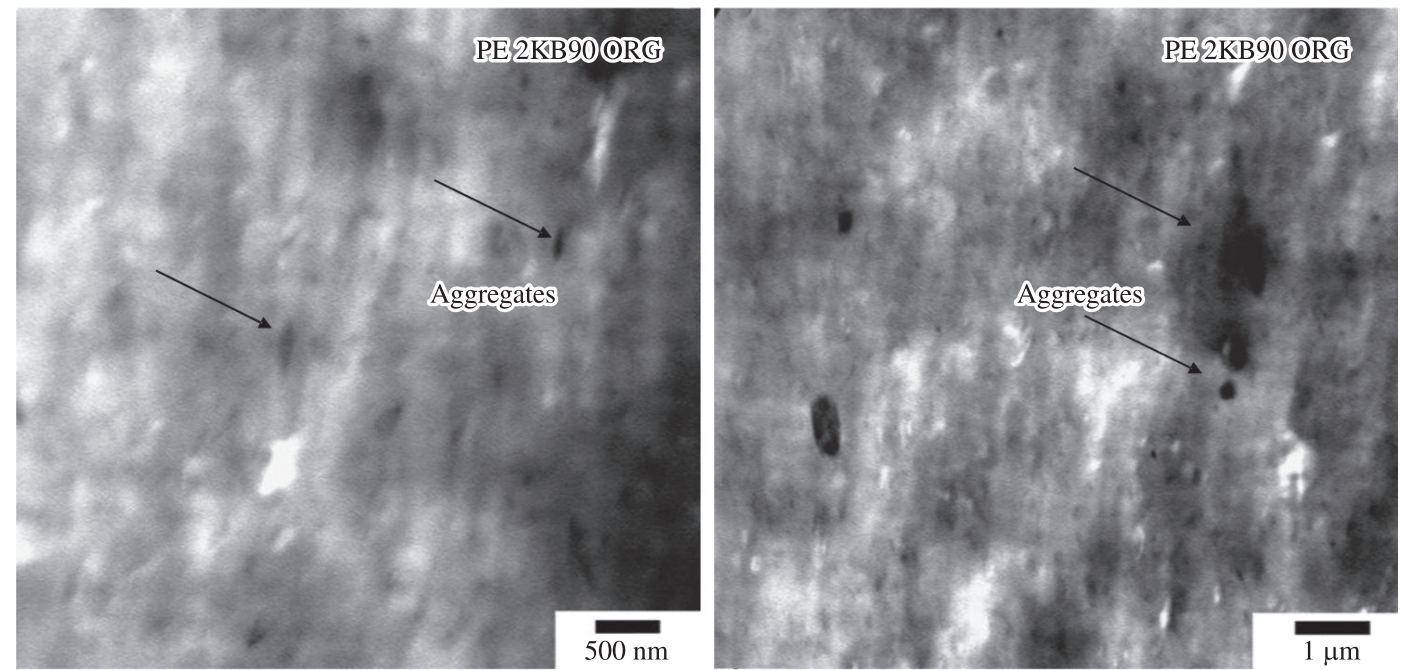

(b)
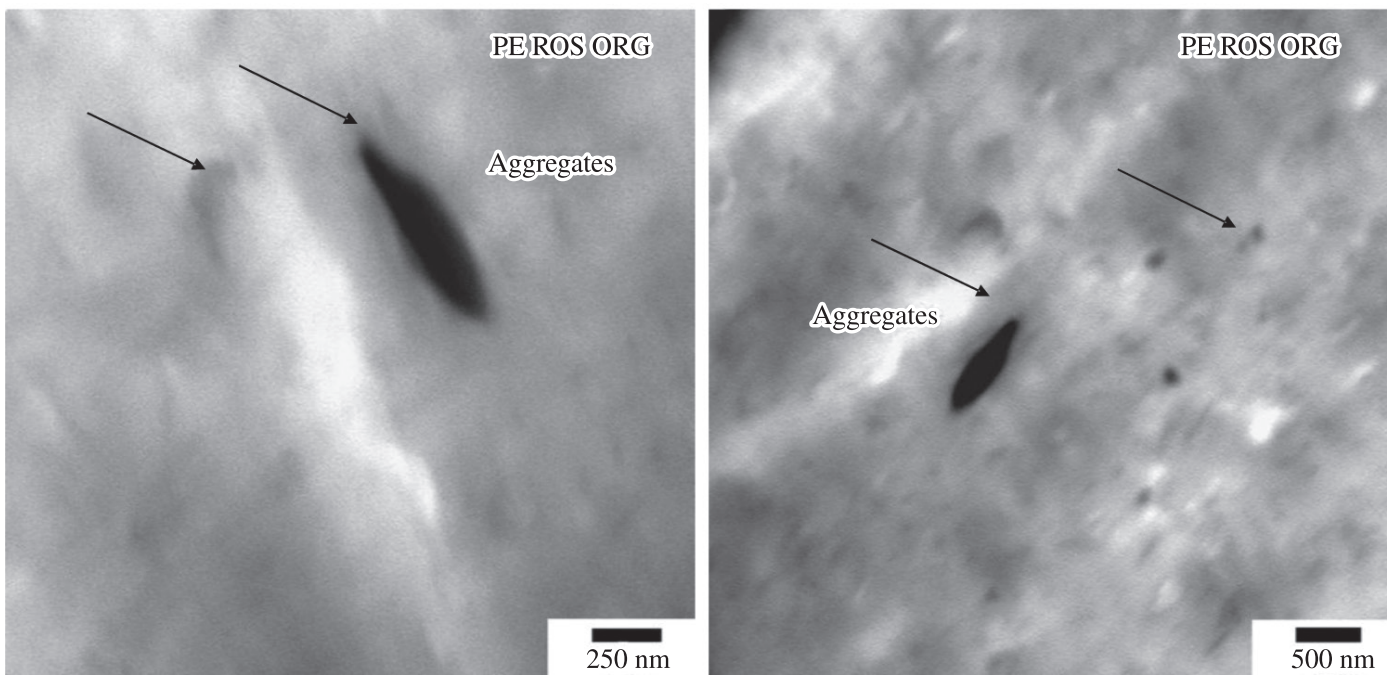

(c)

Figure 3. TEM photomicrographs of the systems processed in two extruders: a) counter- rotating (PE 3009 100) and modular co-rotating b) 2 KB90 and c) ROS 
Table 1. Mechanical tensile properties of HDPE and its nanocomposites.

\begin{tabular}{lcc}
\hline \multicolumn{1}{c}{ System } & $\begin{array}{c}\text { Young modulus } \\
(\mathbf{G P a})\end{array}$ & $\begin{array}{c}\text { Tensile strength } \\
(\mathbf{M P a})\end{array}$ \\
\hline HDPE & $1.13 \pm 0.07$ & $22.17 \pm 0.50$ \\
PE 3009 100 & $1.08 \pm 0.04$ & $24.00 \pm 0.28$ \\
HDPE 2KB90 & $1.20 \pm 0.08$ & $22.92 \pm 0.6$ \\
PE 2KB90 ORG & $1.18 \pm 0.05$ & $22.41 \pm 0.36$ \\
HDPE ROS & $1.26 \pm 0.11$ & $22.87 \pm 0.19$ \\
PE ROS ORG & $1.21 \pm 0,07$ & $22.64 \pm 0.25$ \\
\hline
\end{tabular}

It is observed similar behavior when using the mixture screw (2KB90 or ROS). That is, the modulus and tensile strength of the systems with an organoclay (PE 2KB90 ORG or PE ROS ORG) are reduced when compared to the PE matrix (HDPE 2KB90 or HDPE ROS). Possibly, the fact that the modular co-rotating extruder (method II) was used to encourage greater dispersion, thus exfoliated structures were obtained. However, it is noticed that the processing has not been able to disperse and distribute the load in the polymer matrix successfully. Even the presence of organoclay and the compatibilizer agent was not enough to get the exfoliation, therefore reducing the mechanical properties.

\section{Conclusions}

In this study, high density polyethylene/organoclay nanocomposites were obtained by melt intercalation technique. The nanocomposites processed in the corotating extruder showed basal spacing $\left(\mathrm{d}_{001}\right)$ smaller than the organoclay and nanocomposites processed in the counter-rotating twin-screw extruder, and therefore a morphology of the microcomposite, as observed by TEM.

\section{References}

1. Tabuani D, Ceccia S and Camino G. Polypropylene Nanocomposites, Study of the Influence of the Nanofiller Nature on Morphology and Material Properties. Macromolecular Symposia. 2011; 301:114-127. http://dx.doi.org/10.1002/ masy.201150315

2. Paul DR and Robeson LM. Polymer nanotechnology: nanocomposites. Polymer. 2008; 49:3187-3204. http://dx.doi. org/10.1016/j.polymer.2008.04.017

3. Delbem MF, Valera TS, Valenzuela-Diaz FR and Demarquette NR. Modification of a brazilian smectite clay with different quaternary ammonium salts. Química Nova. 2010; 33(2):309-315. http://dx.doi.org/10.1590/S010040422010000200015

4. Bergaya F, Theng BKG and Lagaly G. Handbook of Clays Science. Amsterdan: Elsevier Science; 2006.

5. Coelho ACV, Santos PS and Santos HS. Argilas especiais: argilas quimicamente modificadas - uma revisão. Química Nova. 2007; 30(5):1282-94.

6. Utracki LA. Clay-Containing Polymeric Nanocomposite. Shawbury: Rapra Technology Limited; 2004. v. 1.

7. Carastan DJ and Demarquette NR. Polystyrene/ clay nanocomposites. International Materials

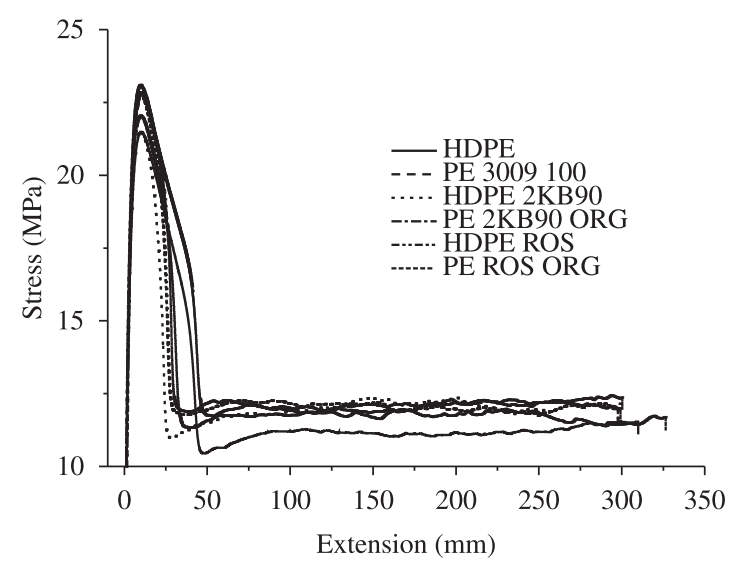

Figure 4. Stress $\times$ strain curves of the nanocomposites.

IIn general, the presence of organoclay, compatibilizer agent and the co-rotating extruder were not sufficient to achieve exfoliation. Similar behaviors were observed when using the mixture screw (2KB90 or ROS). That is, the modulus and tensile strength of the system with an organoclay (PE 2KB90 ORG or PE ROS ORG) were reduced when compared to the PE matrix (HDPE 2KB90 or HDPE ROS).

\section{Acknowledgements}

The authors thank Braskem for the donation of HDPE, Northeast Bentonit Union (BUN) for providing the clay, Clariant/PE for the donation of salt, Laboratory of Materials Engineering/CCT/UFCG (LabMat), Molecular Nanotechnology Network and Interfaces (RENAMI), DEMa/UFSCar, MCT/CNPq, CAPES/PROCAD-NF, for financial support.
Reviews, 2007; 52:345-80. http://dx.doi . org/10.1179/174328007X212517

8. Demarquette NR, Carastan DJ and Valera TS. In recent advances. In: Thomas S and Zaikov G, editors. Polymer Nanocomposites. New York: Nova Science Publishers; 2008. p. 327-378.

9. Brydson JA. Plastics materials. 4th ed. London: Butterwork Scientific; 1982.

10. Bikales NM, Overberger CG and Menges G. Encyclopedia of polymer science and engineering. New York: Jonh Wiley \& Sons; 1986. v. 4.

11. FornesTD, Hunter DL and Paul DR. Nylon 6 nanocomposites from alkylammonium modified clay: The role of alkyl tails on exfoliation. Macromolecules. 2004; 37:1793-1798. http:// dx.doi.org/10.1021/ma0305481

12. Zhao Z, Tang T, Qin Y and Huang B. Effects of surfactant loadings on the dispersion of clays in maleated polypropylene. Langmuir. 2003; 19:7157-59. http://dx.doi.org/10.1021/ la $034575 \mathrm{w}$

13. Hotta $S$ and Paul DR. Nanocomposites formed from linear low density polyethylene and organoclays. 
Polymer. 2004; 45:7639-54. http://dx.doi.org/10.1016/j. polymer.2004.08.059

14. Wang Y, Chen FB, Li YC and Wu KC. Melt processing of polypropylene/clay modified with maleated polypropylene compatibilizers. Composites Part B: Engineering, 2004; 35:111-24. http://dx.doi.org/10.1016/ S1359-8368(03)00049-0

15. Lertwimolnun W and Vergnes B. Influence of compatibilizer and processing conditions on the dispersion of nanoclay in a polypropylene matrix. Polymer. 2005; 46:3462-71. http:// dx.doi.org/10.1016/j.polymer.2005.02.018

16. Zhu J and Wilkie CA. Thermal and fire studies on polystyrene-clay nanocomposites. Polymer International. 2000; 49:1158-1163. http://dx.doi. org/10.1002/1097-0126(200010)49:10<1158::AIDPI505>3.0.CO;2-G

17. Araújo EM, Barbosa R, Oliveira AD, Morais CRS, Mélo TJA and Souza AG. Thermal and mechanical properties of PE/ organoclay nanocomposites. Journal of Thermal Analysis and Calorimetry. 2007; 87(3):811-4. http://dx.doi.org/10.1007/ s10973-006-7758-0

18. Barbosa R, Kojuck LR, Souza DD, Araújo EM and Mélo TJA. Influence of the processing on the morphology and rheological behavior of PE/PE-g-MAMMT nanocomposites. In: Proceedings of the Polymer Processing 24th Annual Meeting-PPS; 2008; Salerno, Itália. Salerno; 2008.

19. Isaac CS. Influência das variáveis do processo de mistura na morfologia e propriedades finais de filmes tubulares de nanocompósitos de polietileno de alta densidade. [Dissertação]. São Carlos: Universidade Federal de São Carlos; 2006

20. Bertolino MK and Canevarolo SV. In-line monitoring of PP/ MMT nanocomposites formation during melt processing. In: Proceedings of the 24th Annual Meeting of the Polymer Processing Society; 2008; Salerno, Itália. Salerno; 2008.

21. American Society for Testing and Materials-ASTM. D638-02: Standard Test Method for Tensile Properties of Plastics. In: American Society for Testing and Materials. Annual Book of ASTM Standards. Philadelphia: ASTM, 2002.

22. Paiva LB, Morales AR and Guimarães TR. Mechanical properties of polypropylene nanocomposites montmorillonite and organoclay. Polymer Science and Technology. 2006; 16(2):136-140.

23. Lee KY and Goetller LA. Structure-property relationships in polymer blend nanocomposites. Polymer Engineering \& Science. 2004; 44(6):1103-1111. http://dx.doi.org/10.1002/ pen. 20103 